\title{
Técnica de condicionamento gengival em reabilitação protética: relato de caso clínico
}

\section{Gingival conditioning technique in prosthetic rehabilitation: a case report}

\section{Resumo}

Introdução: condutas tomadas na fase de planejamento de tratamento, com vistas a conseguir um tratamento protético satisfatório, melhorando a estética de um sorriso, devem preceder procedimentos que possibilitarão condicionar os tecidos moles com auxílio de próteses provisória, visando à formação de um arco côncavo gengival e, consequentemente, de papilas interdentais. Com isso, o perfil de emergência do pôntico evita a formação dos chamados "buracos negros" e o acúmulo de alimento no meio oral reestabelecido. $O$ objetivo da seleção de uma técnica de condicionamento de um rebordo, em formato côncavo, é possibilitar a confecção de próteses fixas mais estéticas, funcionais, no qual o paciente devidamente instruído consiga realizar uma correta higiene. Objetivo e relato de caso: neste trabaIho, será apresentado um caso clínico onde se realizou a técnica de condicionamento por aumento cervical do pôntico, conhecida como aumento gradual da pressão, comparada com a técnica de escarificação gengival, a fim de se obter o condicionamento esperado. Conclusão: conclui-se que, independentemente da técnica a ser realizada, a prótese provisória deve estar fixada na posição correta, pois desde um leve deslocamento até sua soltura ou perda implicará na acomodação gengival a uma nova posição, alterando para uma forma não desejada o "condicionamento gengival" de um dia para o outro rapidamente. Por essa razão, toda prótese provisória, por ser considerada fundamental ao sucesso do tratamento final, deve estar devidamente adaptada, polida e cimentada, sem que haja quaisquer resquícios de cimento, assim como as próteses definitivas, embora no caso clínico aqui relatado tenha sido confeccionada uma prótese adesiva em resina composta sobre uma fita de fibra de vidro.

Palavras-chaves: Condicionamento gengival. Prótese fixa. Pôntico. Estética.

\section{Introdução}

Em pacientes que possuem rebordos alveolares defeituosos ou que sofreram algum tipo de reabsorção, por qualquer razão, como, por exemplo, um defeito ósseo causado pela perda de um elemento dental, é comum encontramos uma condição da arquitetura gengival alterada ou perdida, no que diz respeito à estética e função. Por esse motivo, temos a intenção de explanar sobre técnicas de condicionamento de gengiva, com a finalidade de restabelecer a arquitetura gengival perdida, favorecendo o resultado do tratamento reabilitador.

Para tanto, relatamos um caso clínico atendido na Faculdade de Odontologia (FO) da Universidade de Passo Fundo (UPF). Este trabalho reforça a possibilidade de se realizar um condicionamento gengival em tecidos moles de pacientes que têm rebordos residuais em condições favoráveis à reconstrução do arco côncavo gengival. 


\section{Revisão de literatura}

O tratamento protético restaurador deve sempre ser precedido por uma avaliação periodontal nos dentes pilares, visto que um planejamento integrado proporcionará um prognóstico favorável do tratamento protético restaurador, afirmam Greco et al. ${ }^{1}$ (2009). Ainda, relatam ser necessária uma avaliação quanto ao estado inflamatório dos tecidos, à alteração no contorno gengival, à mobilidade dentária, à profundidade de sondagem e à presença de sangramento e de exsudato.

A restauração dentária deve ser feita nos tecidos livres de inflamação para obter-se sucesso no tratamento. Uma prótese tem a finalidade de restaurar a estética, a função e a saúde do paciente, proporcionando a substituição daqueles dentes naturais ausentes, seja qual for a razão: trauma, destruição dentária, cárie, agenesia, etc., por materiais substitutos de forma mais parecida aos elementos naturais.

Um rebordo atrofiado ou deformado em razão de doença periodontal avançada, formação de abscesso, fratura de tábua óssea após exodontias ou trauma tem como resultado perda de altura, diminuição de espessura e redução da papila interdental ou até seu desaparecimento ${ }^{2}$. A perda do tecido interdental pode ocorrer devido a injúrias traumáticas, cirurgias periodontais, extrações cirúrgicas, defeitos congênitos e escovação imprópria, com consequência da perda óssea, levando o paciente a apresentar dentes com coroas clínicas longas, causando prejuízo estético, conforme definem Carreiro et al. ${ }^{3}$ (2008).

Para obter-se um padrão estético o mais próximo do natural, seja durante o ato cirúrgico, seja na confecção do provisório, há necessidade de um correto manuseio dos tecidos moles, sempre em função do tempo e da resposta individual do paciente, acrescentam Neves et al. ${ }^{4}$ (2000). O pôntico de uma prótese parcial fixa é a réplica anatômica semelhante do elemento dentário ausente, no espaço designado ao dente, cujo desenho deve apresentar características estéticas e funcionais que beneficiam o paciente na higiene oral, como relatam Shilingburg et al. ${ }^{5}$ (2007).

Zavanelli et al. ${ }^{6}$ (2004) acreditam que o condicionamento gengival tem por objetivo melhorar o formato do rebordo residual, em altura e espessura, proporcionando o espaço adequado ao desenho do perfil de emergência do pôntico que será instalado naquele sítio de rebordo em arco côncavo e com papilas interdentais, possibilitando a obtenção de uma prótese parcial fixa estética, funcional e mais biocompatível.

De acordo com Oliveira et al. ${ }^{7}$ (2002), uma pressão excessiva no tecido gengival pode inflamar e até ulcerar o local, ou uma leve pressão terá pouca influência sobre a área, dificultando e prolongando o tratamento protético. Com uma pressão controlada, o pôntico convexo polido e o rígido controle de placa pelo paciente, o epitélio gengival sofre apenas um afinamento, diminuindo suas cristas de tecido conjuntivo, sem presença de inflamação tecidual.

Oliveira et al. ${ }^{7}$ (2002) descrevem as três possíveis técnicas para obter-se o condicionamento gengival em tecidos moles, sendo elas:

1) Pressão gradual: baseia-se na utilização de uma restauração provisória na área do pôntico, que recebe uma aplicação gradual de resina acrílica - em torno de $1,0 \mathrm{~mm}$ de espessura -, a fim de fazer pressão no tecido, modelando-o e levando-o a sofrer uma leve isquemia, sem interferir na adaptação marginal e cimentação da prótese. Indicada para pequenas áreas, em até dois pônticos. Após uma semana, reavaliar a condição gengival da área, sendo necessárias de três a cinco aplicações, em média.

2) Escarificação: após a adaptação da restauração provisória nos pilares, delimita-se o desenho gengival com um lápis que não contenha pigmentos manchando o tecido. Após a anestesia infiltrativa na região, o tecido é esculpido com brocas diamantadas em forma de pera, em alta rotação, com irrigação, criando as concavidades que receberão os pônticos. Após 12 dias, a reparação tecidual estará completa. Indicada para áreas extensas, com mais de um pôntico.

3) Eletrocirurgia: segue os mesmos padrões da técnica de escarificação, porém é feita com pontas de eletrobisturi. Trata-se de uma técnica mais traumática, com longo período de cicatrização, devido à necrose tecidual gerada pelo calor. É contraindicada para pacientes portadores de marcapasso cardíaco.

\section{Relato de caso}

O paciente masculino, 28 anos, compareceu à Clínica Integrada da Faculdade de Odontologia com o desejo de receber uma prótese para repor os elementos 15 e 25 ausentes, como mostram as Figuras $1 \mathrm{~A}$ e $1 \mathrm{~B}$, respectivamente. 

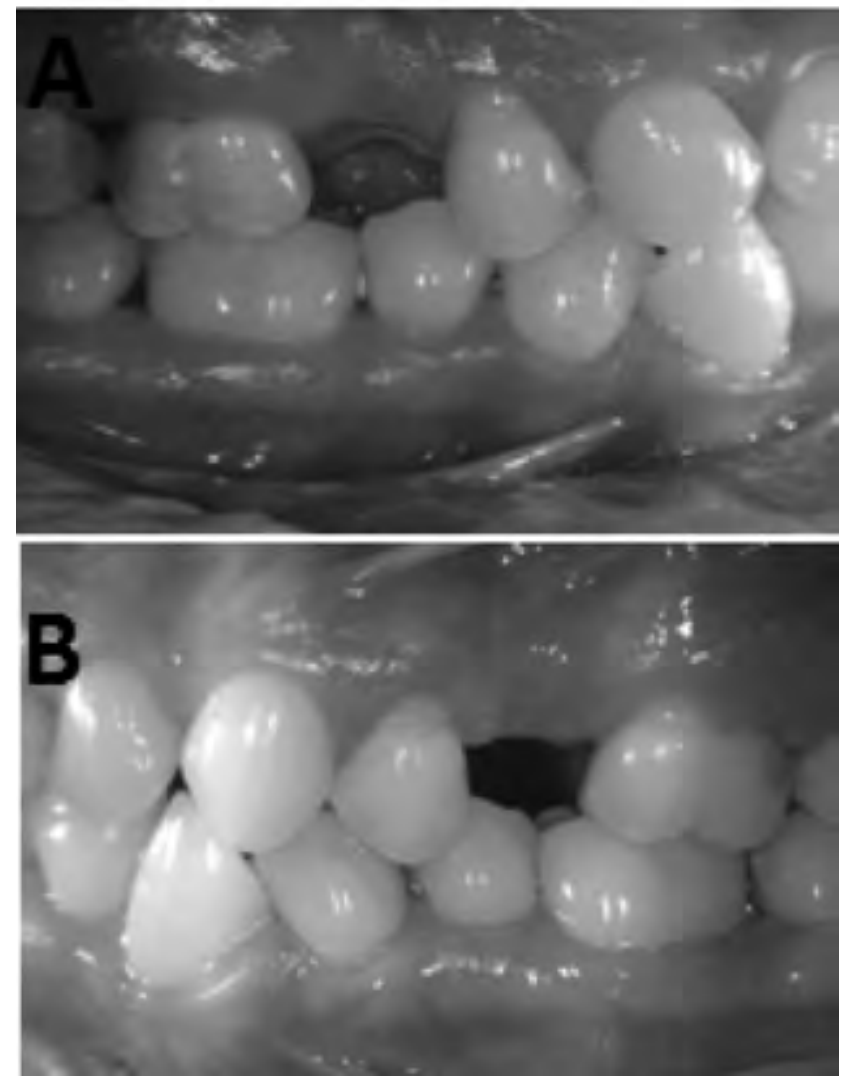

Figura $1 A$ - elemento dentário 15 ausente, lado direito. Figura $1 B$ elemento dentário 25 ausente, lado esquerdo

Para esse caso, considerando fatores socioeconômicos e, também, a preservação da estrutura dentária sadia, optou-se pela confecção de uma prótese fixa adesiva em resina composta fotoativada (Opallis, FGM, Joinville, SC, Brasil) reforçada por fibra de vidro (Interlig, Angelus, Londrina, PR, Brasil), observada na Figura 2A.

Foi realizada a seleção de cor dos dentes do paciente para uma maior aproximação da cor natural. No terço cervical observou-se B3, no terço médio, B2 e na Incisal, A2, a partir da confecção dos modelos de trabalho em gesso pedra e execução da prótese em laboratório observada na Figura 2B.
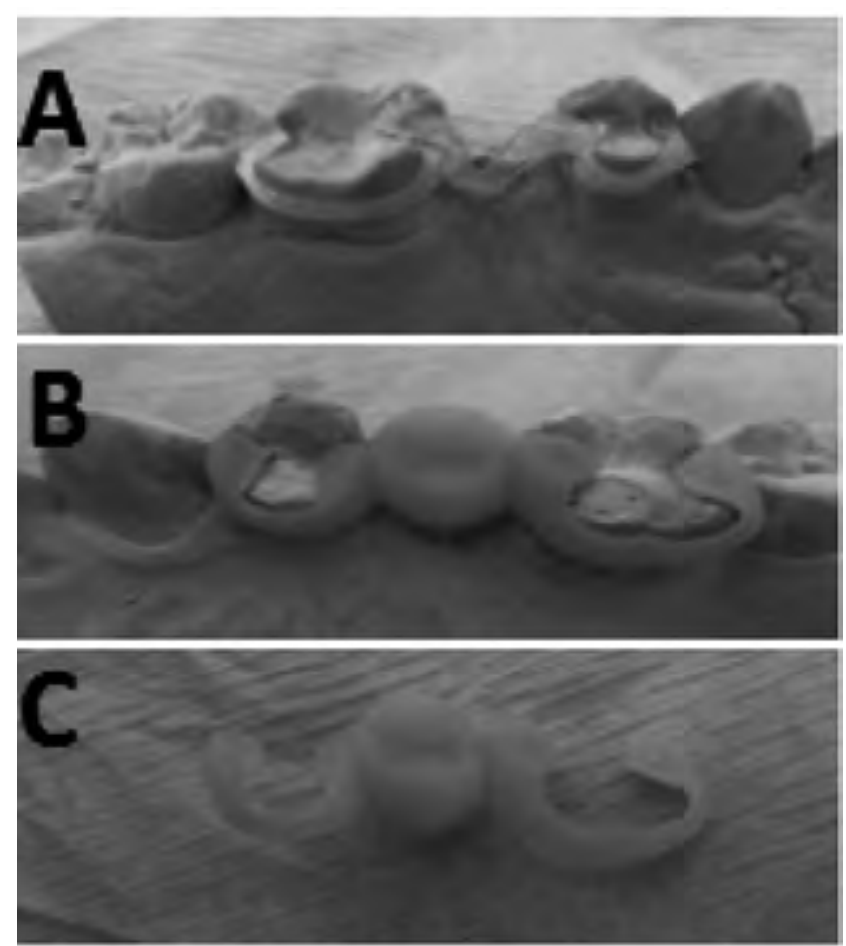

Figura 2A - Fibra de vidro Interlig acomodada no modelo e fotoativada.Figura $2 B$ - Prótese em resina composta Opallis reforçada pela fibra de vidro. Figura 2 C - Prótese provisória em resina composta Opallis.

No lado esquerdo foi feito um preparo na face palatina com aproximadamente $3 \mathrm{~mm}$ de largura e $0,5 \mathrm{~mm}$ de espessura, e nas faces proximais foram confeccionados dois nichos, um na face mesial e outro na distal, terminando $1 \mathrm{~mm}$ aquém do ponto de contato, sem causar prejuízo estético, nos elementos 24 e 26, como mostra a Figura 3, realizados com auxílio de uma caneta de alta rotação e pontas diamantadas 3.215 e 2.131 (KG). O acabamento da superfície dentária preparada para receber tal prótese deverá ser arredondado em suas arestas.

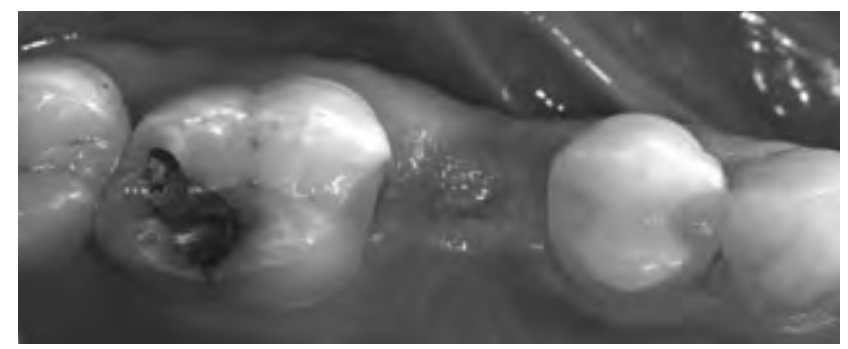

Figura 3 - Preparo na face palatina dos dentes e nichos nas mesiais e distais dos elementos

\section{Técnica I: condicionamento gengival sob pressão gradual}

Foi confeccionada uma prótese provisória fixa adesiva em resina composta (Opalis A2, B2, B3) observada na Figura 2C.

A cada semana acrescentou-se uma fina camada de resina composta no pôntico, observando a isque- 
mia gengival, que, após 2 a 3 minutos, normalizava-se, para que tomasse a forma de bala, para fins de facilitar a escovação e a formação papilar. Durante essa fase, realizou-se um condicionamento gengival através da técnica de aumento gradual sob pressão, adicionando resina composta na região cervical do pôntico, em consultas semanais por 6 semanas (Figuras $4 \mathrm{~A}$ e $4 \mathrm{~B})$.

Após a realização do condicionamento gengival sob pressão gradual, observou-se a formação do arco côncavo gengival e das papilas interdentais, favorecendo na estética e no sorriso do paciente (Figura 4C).
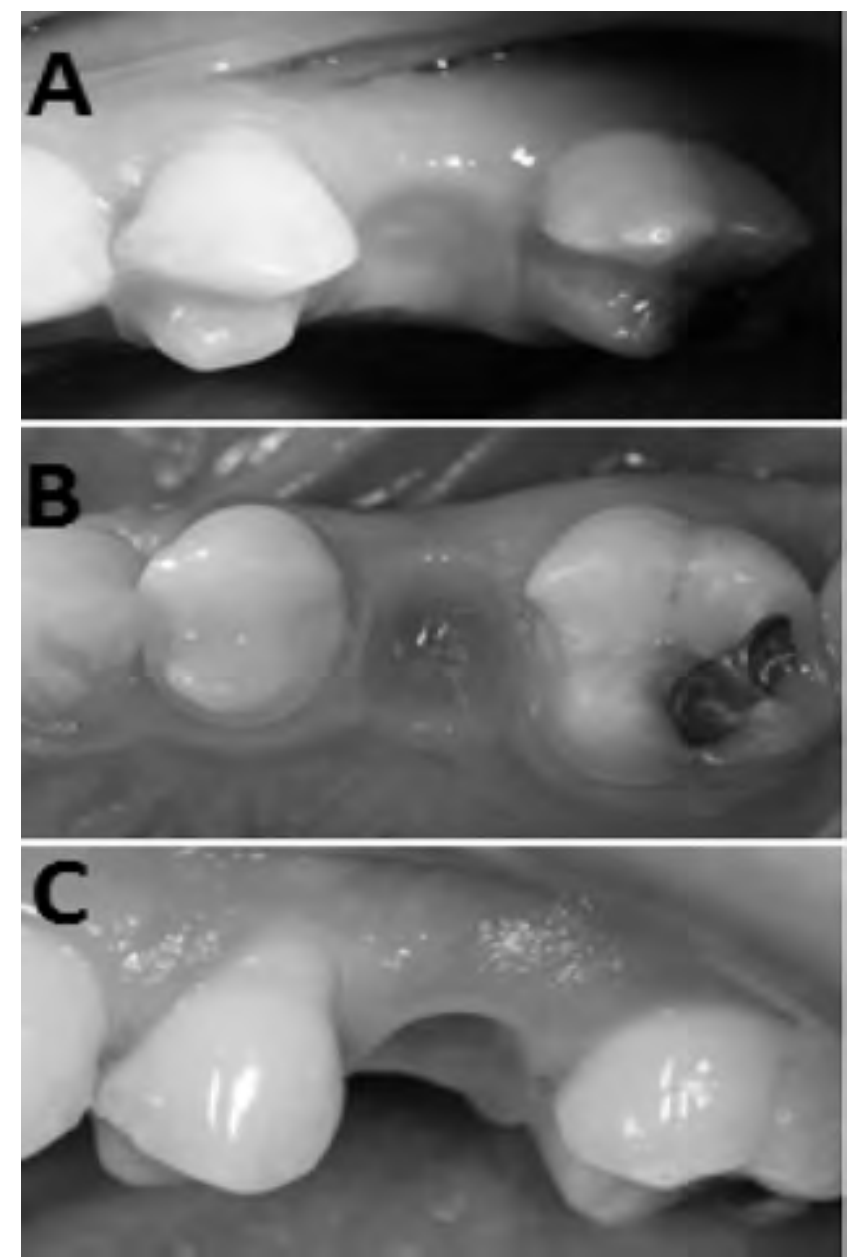

Figura 4A - Após 2 semanas de condicionamento gengival. Figura 4B - Após 6 semanas de condicionamento gengival. Figura $4 C$ - Formação do arco côncavo gengival e das papilas interdentais.

Para a cimentação provisória, semanalmente, após isolamento relativo com roletes de algodão, condicionou-se somente um ponto na face palatina de cada dente com ácido fosfórico $37 \%$ (Acid gel) por 20 segundos. Lavou-se com água abundante e secou-se com bolinha de algodão e, então, aplicou-se o sistema adesivo (Adper Scotchbond Multiuso, 3M ESPE), pincelando com microbrusch e friccionando por 10 segundos, sendo fotoativado por 40 segundos. A cimentação provisória semanal foi feita com resina flow (Natural flow A2), pressionando e mantendo a prótese, em posição, sendo cada face fotoativada por 1 minuto.
Para sua cimentação definitiva, utilizou-se isolamento relativo com roletes de algodão, ambiente seco, e a cimentação foi com cimento resinoso Rely X U100 (3M ESPE, St. Paul, MN, EUA), sendo cada face fotoativada durante 1 minuto. Para o tratamento da superfície da peça em resina composta, foi utilizado ácido fosfórico $37 \%$ por 20 s, sistema adesivo e fotoativado.

Após a cimentação definitiva, foi possível observar as próteses com estética satisfatória, ficando o paciente satisfeito pelo baixo custo.

\section{Técnica II: condicionamento gengival com escarificação gengival}

No lado esquerdo foram realizados os preparos, a confecção da prótese semelhante ao lado oposto.

Num primeiro momento, foi utilizado um lápis cópia Faber Castell 1800 para desenhar o arco côncavo gengival, verificando a adaptação da prótese naquele desenho (Figura 5A). Para a formação do arco côncavo gengival foi realizada a técnica de escarificação gengival. Inicialmente, foram realizadas a aplicação de anestésico tópico e a anestesia infiltrativa na gengival ao redor do local da escarificação com lidocaína $2 \%$. Com a sonda milimetrada periodontal, observou-se $4 \mathrm{~mm}$ de profundidade gengival até o osso (Figura 5B).

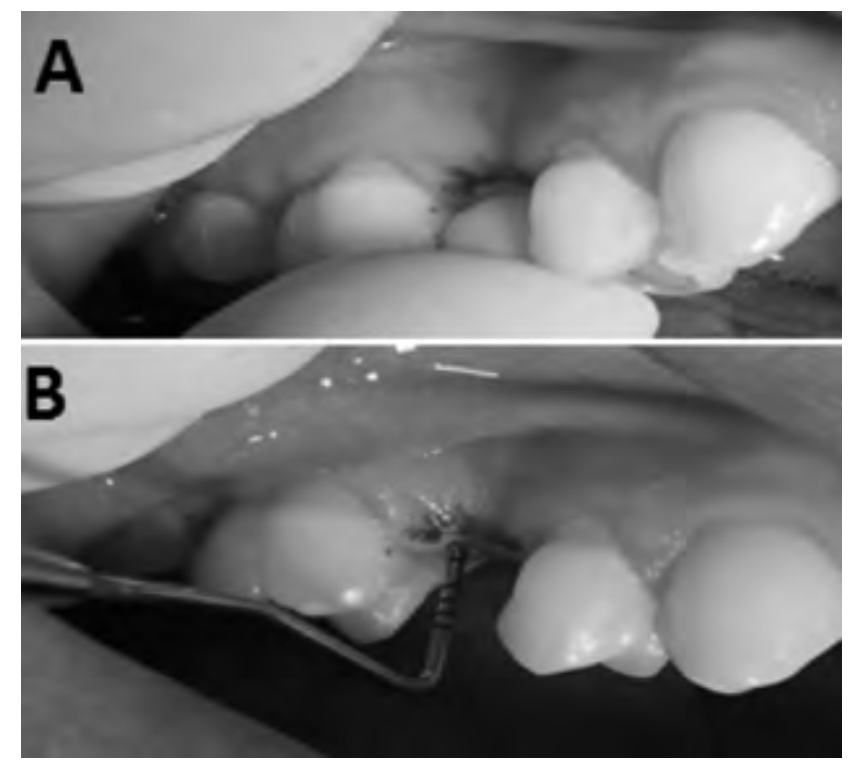

Figura 5A - Arco côncavo desenhado e verificação da adaptação da prótese. Figura 5B - Sondagem para verificar a profundidade e a preservação da crista óssea.

Com a caneta de alta rotação e as brocas diamantadas $3118 \mathrm{~F}$ e 1016 (KG), sob irrigação, desgastou-se cerca de $2,5 \mathrm{~mm}$ de gengiva, a fim de reproduzir a concavidade gengival, devolvendo as papilas interdentais e a estética (Figura 6). 


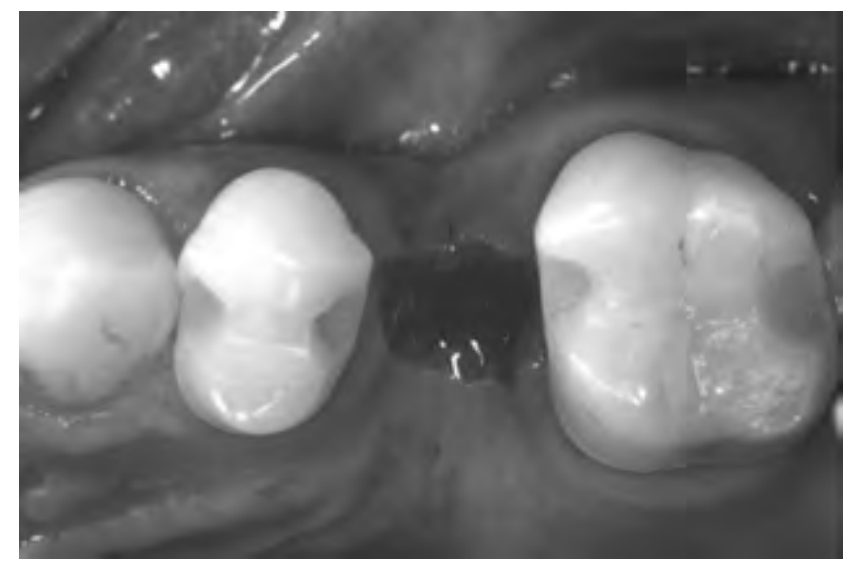

Figura 6 - Aspecto final após a escarificação gengival

Após a escarificação gengival e a coagulação da região, com isolamento relativo, o tratamento da peça procedeu-se de forma semelhante ao lado oposto, conforme descrito acima. Procedeu-se à cimentação definitiva com cimento resinoso Rely X U100 (3M ESPE, St. Paul, NM, EUA). Pressionando a prótese e mantendo-a em posição, a peça foi fotoativada por 1 minuto em cada face.

A prótese cimentada e finalizada com estética satisfatória pode ser observada nas Figuras 7A e 7B.
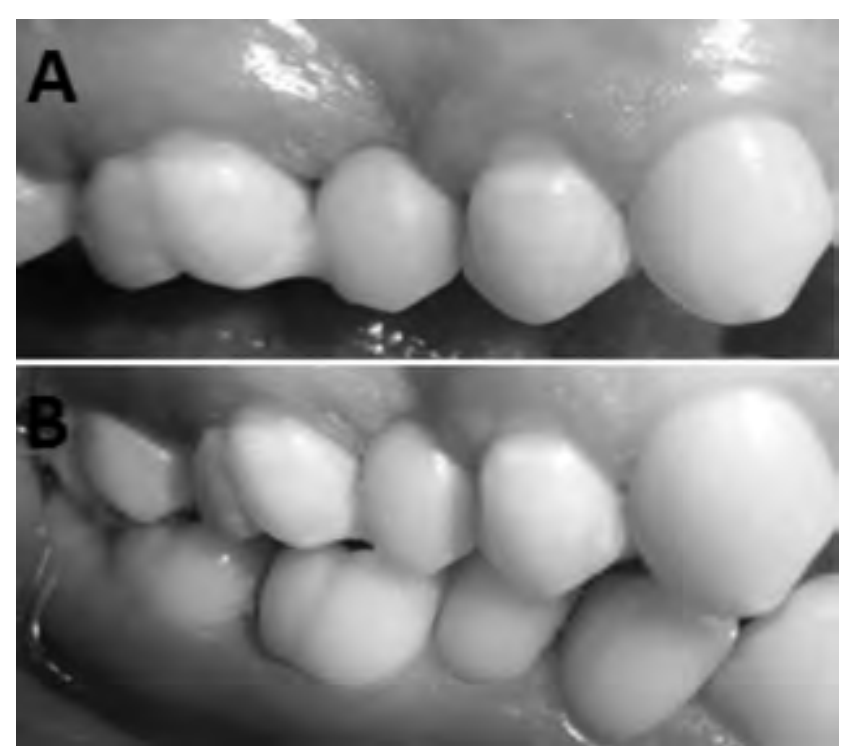

Figura 7A - Vista por vestibular. Figura 7B - Prótese em oclusão.

Radiografias periapicais para observação da crista óssea preservada, observadas nas Figuras 8A e 8 B.

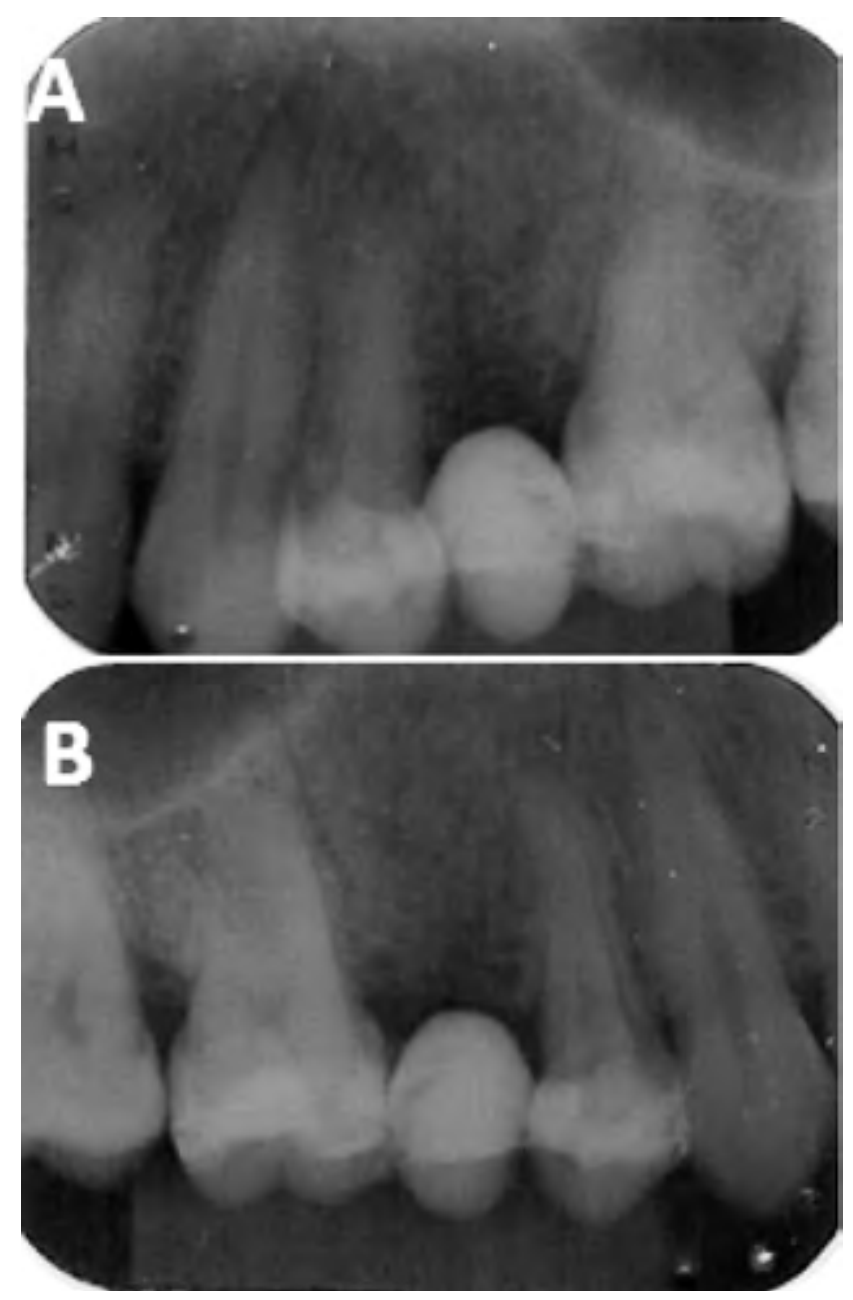

Figura $8 A$ - Radiografia periapical superior direita. Figura $8 B$ - Radiografia periapical superior esquerda.

\section{Discussão}

De acordo com Greco et al. ${ }^{1}$ (2009), a ausência de elementos dentários pode ocorrer devido a extrações cirúrgicas precoces, sendo tais elementos substituídos por uma restauração protética. A consequência dessa perda precoce é a perda do tecido gengival interdental ou papila interdental, o que prejudica a estética ${ }^{3}$.

Uma das condutas clínicas satisfatórias, com o objetivo de maximizar a estética, é, com auxílio de uma prótese provisória, fazer a reconstrução do arco côncavo gengival através das técnicas de condicionamento sob pressão gradual ou escarificação gengival, eliminando os chamados "buracos negros" e beneficiando a estética, conforme relatam Oliveira et $\mathrm{al.}^{7}$ (2002).

O perfil de emergência é definido como o contorno do dente que se estende da base do sulco até a margem gengival livre, até a altura da face lingual e para as áreas de contatos proximais, o que ajuda a promover saúde gengival e prevenir a retenção de placa bacteriana ${ }^{8}$. 
O pôntico, uma réplica semelhante à estrutura dentária ausente, deve ter formato oval e ser extremamente polido, para facilitar a higiene oral do paciente, que é considerada um fator primordial para o sucesso do tratamento, como descrevem Shilingburg et al. ${ }^{7}$ (2007).

A técnica de condicionamento sob pressão gradual necessita de um tempo clínico mais prolongado, porém é menos invasiva e mais controlada. Não remove gengiva, apenas a remodela, facilitando na estética. O tempo clínico mais prolongado é compensado pela necessidade de não desgastar, e sim de remodelar o tecido gengival. Entretanto, embora a técnica de escarificação gengival ocupe um tempo clínico menor, é mais invasiva, removendo o tecido mole, a fim de recortar e desenhar o formato côncavo, deixando um leito cruento, e torna mais difícil o controle do ambiente seco para a cimentação. Assim, a escarificação gengival é mais rápida, mas os resultados são menos satisfatórios (Tabela 1).

Tabela 1 - Comparação entre as técnicas de condicionamento gengival e pressão gradual

\begin{tabular}{l|c|c}
\cline { 2 - 3 } & Escarificação gengival & Pressão gradual \\
\hline Tempo clínico & Menor & Maior \\
Técnica & Mais invasiva & Menos invasiva \\
Gengiva & Remove & Remodela \\
Estética & Pior & Melhor \\
Resultados & Menos satisfatórios & Mais satisfatórios \\
\hline
\end{tabular}

\section{Conclusão}

Conclui-se que, independentemente da técnica a ser realizada, a prótese provisória deve estar fixada na posição correta, pois desde um leve deslocamento até sua soltura ou perda implicarão na acomodação gengival a uma nova posição, alterando para uma forma não desejada o "condicionamento gengival" de um dia para o outro rapidamente. Por essa razão, toda prótese provisória, por ser considerada fundamental ao sucesso do tratamento final, deve estar devidamente adaptada, polida e cimentada.

\section{Abstract}

Introduction: procedures made in the treatment planning stage aiming to achieve a satisfactory prosthetic treatment and improve smile esthetics must forego procedures that will allow the conditioning of soft tissues with the aid of temporary prostheses, in order to form a gingival concave arch, and hence, interdental papillae. Thus, the emergence profile of pontics prevents the creation of so-called "black holes", and reestablishes the accumulation of food in the oral environment. The goal of selecting a margin conditioning technique in a concave shape which allows the fabrication of more esthetic and functional fixed prostheses is for the patient, properly instructed, to perform a correct hygiene. Objective and case report: this paper shows a clinical case where the technique of conditioning by cervical pontic augmentation, known as gradual increase in pressure was performed and compared to the technique of gingival scarification, in order to obtain the expected conditioning. Conclusion: it is concluded that, regardless of the technique applied, the temporary prosthesis must be set in the correct position because, either a slight displacement or its release or loss will result in gingival accommodation to a new position, quickly changing it to an unwanted shape of "gingival conditioning". Therefore, the entire temporary prosthesis considered essential to the success of the final treatment must be properly adjusted, polished, and cemented without any traces of cement, as well as permanent prostheses, although in the clinical case hereby reported an Adhesive Prosthesis in Composite Resin was made on a glass fiber tape.

Keywords: Gingival conditioning. Fixed prosthesis. Pontic. Esthetics.

\section{Referências}

1. Greco GD, Da Costa V, Greco ACDL, Rocha WMS, Lanza MD. A importância do planejamento integrado no tratamento da reabilitação oral. ImplantNews 2009; 6(1):57-64.

2. Machado WAS, Machado Jr. DZ, Silva Jr. JA da S, Kahn S. Aumento de coroa clínica: com condicionamento de rebordo e reconstrução da papila interdental. RGO 2005; 53(2):85-164.

3. Carreiro AFP, Moraes S, Branco N, Guerral CMF, Amaral BA. Epítese gengival removível: alternativa estética e de rápida resolução para repor tecidos periodontais anteriores. RGO 2008; 56(4):451-5.

4. Neves FD, Neto AJF, Prado CJ. Moldagem do implante durante o primeiro estágio cirúrgico. RGO 2000; 48(4):230-4.

5. Shillingburg Jr. HT, Hobo S, Hitsett LD, Jacobi R, Brackett SE. Fundamentos de prótese fixa. São Paulo: Quitessence; 2007. p. 397-415.

6. Zavanelli AC, Dekon SF de C; Zavanelli RA, Mazaro JVQ, Nepomuceno VC, Fernandes AUR. Condicionamento gengival. PCL 2204;6(32):357-63.

7. Oliveira JA, Ribeiro ÉDP, Conti PCR, Do Valle AL, Pegoraro LF. Condicionamento gengival: estética em tecidos moles. Rev Fac Odontol Bauru 2002; 10(2):99-104.

8. Azer SS. A simplified technique for creating a customized gingival emergence profile for implant-supported crowns. Journal of Prosthodontics 2010; 19:497-501.

\section{Endereço para correspondência:}

Sandra Eloisa Drey

Rua Silva Jardim, 1490, Centro

99500-000 Carazinho/RS

Fone: (54) 9967-1609

E-mail: drey_dentistasandra@hotmail.com

Recebido: 08/11/2013. Aceito: 26/02/2014. 